University of Nebraska - Lincoln

DigitalCommons@University of Nebraska - Lincoln

Sociology Department, Faculty Publications

Sociology, Department of

2006

\title{
Mental Disorders, Comorbidity, and Postrunaway Arrests Among Homeless and Runaway Adolescents
}

\author{
Xiaojin Chen \\ Tulane University \\ Lisa Thrane \\ Wichita State University \\ Les B. Whitbeck \\ University of Nebraska-Lincoln, Iwhitbeck2@unl.edu \\ Kurt Johnson \\ University of Nebraska-Lincoln
}

Follow this and additional works at: https://digitalcommons.unl.edu/sociologyfacpub

Part of the Sociology Commons

Chen, Xiaojin; Thrane, Lisa; Whitbeck, Les B.; and Johnson, Kurt, "Mental Disorders, Comorbidity, and Postrunaway Arrests Among Homeless and Runaway Adolescents" (2006). Sociology Department, Faculty Publications. 34.

https://digitalcommons.unl.edu/sociologyfacpub/34

This Article is brought to you for free and open access by the Sociology, Department of at DigitalCommons@University of Nebraska - Lincoln. It has been accepted for inclusion in Sociology Department, Faculty Publications by an authorized administrator of DigitalCommons@University of Nebraska - Lincoln. 


\title{
Mental Disorders, Comorbidity, and Postrunaway Arrests Among Homeless and Runaway Adolescents
}

\author{
Xiaojin Chen \\ Tulane University \\ Lisa Thrane \\ Wichita State University \\ Les B. Whitbeck and Kurt Johnson \\ University of Nebraska-Lincoln \\ Corresponding author - Xiaojin Chen, Tulane University, \\ Department of Sociology, 220 Newcomb Hall, New Orleans, LA 70118. \\ Telephone 504-862-3016. Email xchen1@tulane.edu
}

\begin{abstract}
This study examined the associations between lifetime mental disorder, comorbidity, and self-reported postrunaway arrests among 428 (187 males, 241 females) homeless and runaway youth. The analysis examined the pattern of arrests across five lifetime mental disorders (alcohol abuse, drug abuse, conduct disorder, major depressive episode, and posttraumatic stress disorder). The adolescents, ranging from 16 to 19 years old, were interviewed directly on the streets and in shelters in four Midwestern states using computer-assisted personal interviewing. Extensive self-reports of early life history, behaviors since running away from home, and diagnostic interviewing (UM-CIDI and DISC-R) were used to estimate possible disorders. There was a high level of postrunaway arrests reported by the youth; more than half were arrested at least once after the initial runaway, with the average of 4.4 times. Consistent with the hypotheses, there were differential associations between individual mental disorders
\end{abstract}


and involvement with the criminal justice system. Only externalizing disorders such as substance abuse and conduct disorder were related to arrest. Street youth with multiple externalizing and internalizing disorders were more likely to be arrested than nondisordered youths.

Past research suggests that homeless and runaway adolescents are heavily involved in delinquency and criminal activity (Baron \& Hartnagel, 1997a, 1997b; Hagan \& McCarthy, 1997; McCarthy \& Hagan, 1992) and thus are much more likely to be arrested than housed youth (Hagan \& McCarthy, 1997; Kaufman \& Widom, 1999; McCarthy \& Hagan, 1992; Whitbeck \& Hoyt, 1999). In addition, high rates of mental health disorders such as alcohol and drug abuse, conduct disorder, major depression, posttraumatic stress disorder (PTSD), suicide ideation, suicidal attempts, and comorbidity, have been reported among homeless youth (Cauce et al., 2000; Feitel, Margetson, Chamas, \& Lipman, 1992; McCaskill, Toro, \& Wolfe, 1998; Whitbeck, Johnson, Hoyt, \& Cauce, 2004).

Numerous studies have examined the linkage between mental disorder and crime in the general population (for recent reviews see Crichton, 1999; Hodgins, Mullersberner, \& Maden, 2001). Although the public has been greatly concerned with delinquency and criminal behavior among homeless mentally ill youth, very few studies have explored the association among homeless people, especially homeless adolescents (Belcher, 1988; Booth \& Zhang, 1996; Brenda, 2003; Desai, Lam, \& Rosenheck, 2000; Fischer, 1988; Martell, Rosner, \& Harmon, 1995; Snow, Baker, \& Anderson, 1989). A few studies suggest a positive association between mental disorder and involvement with the criminal justice system, the association, however, is still poorly understood because most studies employ a broad definition of mental illness and do not differentiate various types of disorders. For example, samples were selected based on services received (e.g., the use of hospitalization) instead of the presence of a specific disorder (Belcher, 1988; Brenda, 2003; Fischer, 1988; Martell et al., 1995; Snow et al., 1989).

As suggested by Hodgins (1988), mental disorders differ considerably in symptomatology, course, response to treatment, and etiology. As a result, it is reasonable to assume that associations between these mental disorders and criminality differ. There are at least three possible relations between mental disorder and crime: positive, negative, and the absence of an association (Hodgins, 1988). Grouping various disorders could mask any association that does exist. In addition, a broad definition of mental illness covers up the effects of comorbidity on arrest and other negative social consequences. As suggested by Kessler and his colleagues (Kessler, 
1994, 1995; Kessler, Foster, Saunders, \& Stang, 1995; Kessler, Walters, \& Forthofer, 1998), dual-diagnosis such as substance abuse and other mental disorders have more adverse effects than single diagnoses. Considering the prevalence of mental disorder, comorbidity, and delinquency among homeless adolescents, studies are needed to disentangle the association between various types of mental disorder and comorbidity and involvement with the criminal justice system.

The current study uses data from the Midwest Longitudinal Study of Homeless Adolescents to examine the association between specific mental disorder and postrunaway arrest. First, this study will examine arrest patterns across five individual mental health disorders (alcohol abuse, drug abuse, conduct disorder, major depression, and posttraumatic stress disorder). Second, following Kessler's (1994, 1995) recommendation, we will assess the relationship between comorbidity and postrunaway arrest. In addition, to obtain unbiased estimates of individual mental disorders and comorbidity, this study will employ multivariate logistic regression models, which control for demographic and situational risk factors.

\section{Mental Disorder, Comorbidity, and Criminality}

The association between mental disorder and crime has been long debated. Although numerous investigations have found that mental disorder and criminality are related (Crichton, 1999; Hodgins et al., 2001), the nature of the relationship is still elusive. One major obstacle involves operationalizing mental disorder per se. More than 300 mental disorders are listed in the DSM-IV and each has its own symptom, course, response to treatment, and etiology. As Hodgins (1993) suggested, specific mental disorders may have varying influences on criminality. One objective of research is to identify the association (or lack of association) between various mental disorders and crime.

Past studies have provided strong and consistent support that externalizing disorders such as alcohol abuse, drug abuse, and disruptive behavior or antisocial personality are associated with criminal offending and arrest (Fergusson \& Horwood, 2000; Friedman, 1998; Hodgins et al., 2001; Loeber \& Leblanc, 1990). It is well known that conduct disorder during childhood and adolescence predicts juvenile delinquency and crime (Loeber \& LeBlanc, 1990), which results in criminal justice involvement. In addition, previous studies have found that alcohol abuse and/ or drug abuse leads to delinquent behavior and crime, and contact with the police (see review, Friedman, 1998). Alcohol abuse among young people is significantly associated with violent and property crime (Fergus- 
son \& Horwood, 2000); similarly, drug abuse predicts violent behavior for males as well as females (Friedman, 1998).

The association between internalizing disorders and involvement with the criminal justice system is more complex. Although past studies have found that major depression is highly associated with violent behavior and crime (Hodgins, 1993; Robins, 1993; Steadman et al., 1998; Stueve \& Link, 1997), the precise nature of this relationship has not been explored. Individuals may try to alleviate depression by engaging in illegal acts (Agnew, 1992; Brezina, 1996, 2000), or the association could be spurious since depression and law violation may have a common antecedent and result from a similar process (Coster \& Heimer, 2001). In contrast, studies have indicated that other internalizing disorders, such as PTSD, are not associated with criminality. Past studies have found that PTSD is mostly the result of victimization such as early child abuse, witnessing violence, and physical or sexual trauma (Simpson \& Simpson, 1997). In sum, studies have shown that various externalizing and internalizing disorders result in different levels of criminal justice involvement and call for more diagnostic studies to further our understanding of the relationship.

A relatively less examined area is the association between comorbidity and violence and criminality. Studies have shown that comorbidity among psychiatric disorders is prevalent; more than half of individuals with a lifetime history of one psychiatric disorder have a second diagnosis (Kessler, 1994, 1995). Although the causal association between criminality and comorbidity is not clear, limited research shows that comorbidity is associated to violence and crime (Friedman, 1998; Hodgins, 1993; Hodgins \& Janson, 2002) and other analogous behaviors such as conflictual social relationships (Forthofer, Kessler, Story, \& Gotlib, 1996; Silver, 2002), accidents, fights, and drunken driving arrests (Tomasson \& Vaglum, 1998), and violent incidents (Mulvey, 1994). Specifically, studies have found that various combinations of mental disorders are associated with violence and crime (Hodgins, 1993; Hodgins \& Janson, 2002). For example, comorbid substance abuse such as alcohol abuse and drug abuse increases the risk of offending, violent offending, and arrest (Hodgins \& Janson, 2002). In addition, individuals with a major mental disorder and a secondary diagnosis of substance abuse are more likely to be arrested than those with only a major mental disorder (Friedman, 1998; Hodgins, 1993; Hodgins \& Janson, 2002; Tomasson \& Vaglum, 1998). Personality disorder such as conduct disorder is highly associated with substance abuse, adult antisocial behavior, and other mental disorders; the comorbidity of conduct disorder and other mental disorders is strongly associated with criminality and arrest (Robins, 1993). 


\section{Runaway and Homeless Adolescents}

Although recent studies have found a high prevalence of mental disorder and comorbidity among homeless youth (Cauce et al., 2000; Feitel et al., 1992; McCaskill et al., 1998; Whitbeck, Chen, Hoyt, Tyler, \& Johnson, 2004), there is little research about mental disorder and criminality with one exception (Booth \& Zhang, 1996). Booth and Zhang (1996) examined the prevalence of severe aggressive behavior and conduct disorder in 219 runaway and homeless adolescents (aged 12-19), and found that youth diagnosed with conduct disorder were more likely to be arrested. A few studies examined prevalence of delinquency and criminal behavior among homeless youth and indicated that alcohol and drug use, and other disruptive behaviors were significant predictors (Baron \& Hartnagel, 1997a, 1997b; McCarthy \& Hagan, 1992). These studies, however, did not evaluate whether problem behavior reached clinical thresholds and thus did not examine the association between mental disorder and delinquency and criminal behavior.

A few studies have examined the relationship among homeless adults but provided mixed results (Belcher, 1988; Brenda, 2003; Desai et al., 2000; Fischer, 1988; Martell et al., 1995; Snow et al., 1989). Many have found a positive association between mental disorder and arrest (Belcher, 1988; Desai et al., 2000; Fischer, 1988; Martell et al., 1995). Compared with the domiciled mentally ill population, the overall rate of criminal offense was much higher in homeless mentally ill population (Martell et al., 1995). Alcohol and substance abuse seems to be a major predictor of criminal offense and arrest (Fischer, 1988). In addition, homeless people with severe mental disorders were more likely to be arrested, mainly because of their disruptive behavior and unwillingness or inability to take prescribed medications (Belcher, 1988). Brenda (2003), however, found that although alcohol treatment was significantly associated with current arrest, psychiatric hospitalization did not even have a significant bivariate association. The inconsistency may be due to sampling and measurement issues such as nonstandardized measurement of mental disorders, lack of variation in age, gender, and crime and delinquency, and small sample sizes.

\section{Present Study and Hypotheses}

Although most literature regarding the homeless population has found a linkage between mental disorder and involvement with the criminal justice system, many of them employed a broad definition of mental disorder and failed to examine the unique associations between individ- 
ual mental disorders/comorbidity and crime. In addition, the majority of these studies focused only on homeless adults. Some of them had small samples, issues of operational validity of mental disorder, or little variation in age, gender, and criminal involvement. Hiday (1999) cautioned against generalizing these results to the homeless population and called for more studies using standardized instruments to assess relationships between various mental disorders and criminal activities.

The current study improves on previous research in several respects. First, this study uses standardized instruments such as the University of Michigan Composite International Diagnostic Interview (UM-CIDI) to assess lifetime major depressive episodes, posttraumatic stress disorder, alcohol abuse, and drug abuse, and the Diagnostic Interview Schedule for Children-Revised (DISC-R) to assess lifetime conduct disorder. Second, our sample focused on homeless adolescents ranging in age from 16 to 19 years old. Based on a more geographically diverse sample, 428 adolescents were interviewed directly on the streets and in shelters in eight cities in four Midwestern states. Third, we used a multivariate approach to examine the associations between mental disorder and comoribidty and postrunaway arrest. By applying a multivariate logistic regression model, the effects of environmental risk factors were controlled which allows for unbiased estimates.

Based on previous findings, we hypothesize that the type of mental disorder as well as comorbidity will be associated with postrunaway arrest. Specifically, we hypothesize that externalized mental disorder such as alcohol abuse, drug abuse, and conduct disorder will be significantly and positively associated with postrunaway arrest. In addition, we hypothesize that major depression will be significantly associated with postrunaway arrest; however, we hypothesize that there is no direct relationship between PTSD and arrest. Furthermore, although the association between comorbidity and violence and crime may vary, overall, we expect that adolescents with comorbid disorders are more likely to be arrested than nondisordered adolescents.

Because there is evidence that risk factors contribute to an association between various mental disorders/comoribidity and arrest (Hodgins, 1993, Hodgins \& Janson, 2002), we will employ multivariate logistic regression models to investigate whether these relationships exist after other factors are controlled. We hypothesize that older adolescents, males, nonwhites, and heterosexual adolescents will be more likely to be arrested as they are more likely to engage in delinquent behavior while on the street (Chen, Tyler, Whitbeck, \& Hoyt, 2004; Tyler, Hoyt, Whitbeck, \& Cauce, 2001; Whitbeck et al., 2004). Based on findings pertaining to family abuse and neglect (Hagan \& McCarthy, 1997; Whitbeck \& Hoyt, 
1999), we hypothesize that abusive family backgrounds will have direct effects on involvement with the criminal justice system. Because running away at an early age often results in potentially longer street exposure and is an indicator of earlier serious problem behaviors (Hagan \& McCarthy, 1997; Whitbeck \& Hoyt, 1999), we hypothesize that youth who had run away for the first time at an earlier age and who had spent time directly on the streets will be more likely to be arrested. Finally, consistent with previous studies (Hagan \& McCarthy, 1997; Whitbeck \& Hoyt, 1999), we hypothesize that use of deviant subsistence strategies while on the street increases the odds of police encounters and arrests.

\section{Method}

\section{Sample and Procedure}

Four hundred twenty eight (187 males; 241 females) homeless youth were interviewed directly on the streets and in shelters in eight Midwestern cities (St. Louis, Kansas City, Omaha, Lincoln, Des Moines, Cedar Rapids, Iowa City, and Wichita). We designed a sampling strategy for the current study that incorporated sampling units of fixed and natural sites similar to the design used by Kipke in her Los Angeles study of homeless youth (Kipke, Montgomery, Simon, \& Iverson, 1997) with a year long window of sampling to capture the time dimensions. The sampling design involved repeatedly checking location where homeless youth were likely to be found in each of the target cities. Locations included shelters and outreach programs serving homeless youth, drop-in centers, and various "street" locations where young homeless people were most likely to be located. Research has demonstrated that using sampling designs that involve multiple points of entry to homeless populations are most effective in generating a diverse sample (Burt, 1996; Koegel, Burnam \& Morton, 1996). The interviewers all had prior experience in their respective cities as youth outreach workers and brought considerable knowledge regarding optimal areas of the city for locating youth on their own. The sampling protocol included going to these locations in the cities at varying times of the day on both weekday and weekends over the course of 12-months. As episodes of homelessness are of varying duration, a 1-year time frame provided an increased probability of capturing youth who have short term exposure to homelessness. The interviewers were instructed to continue recruiting until their caseload reached 60 adolescents whom they would then track and reinterview at 3-month intervals.

Street interviewers underwent 2 weeks of intensive training regarding computer-assisted personal interviewing (CAPI) procedures and admin- 
istering the four indices (major depressive episodes, posttraumatic stress disorder, alcohol use/abuse, and drug use/abuse) from the University of Michigan-Composite International Diagnostic Interview (UM-CIDI) and one index (conduct disorder) from the DISC-R. They then returned to their shelters and administered several "practice" interviews with staff and respondents 20 years or older. After completing their practice interviews, the interviewers returned to the university for a second week of training. All interviews were conducted on lap top computers and electronically downloaded to a secure university server.

All participants were between the ages of 16 and 19 years and met the study's criteria for homelessness. "Homelessness" was defined as residing in a shelter, on the street, or living independently (e.g., friends, transitional living, etc.) because they had run away, been pushed out, or drifted out of their families of origin. Sixty-one percent of males interviewed and $39 \%$ of females had spent at least one night directly on the streets. When asked where they stayed "last night" (i.e., night before interview), 40\% had spent the night before in a shelter, $11 \%$ in a relative's home, $16 \%$ in the home of a friend or "acquaintance," $16 \%$ in a foster/ group home (operated by the street agency), $6 \%$ in their own apartment (transitional living programs operated by a street agency), and a little more than $10 \%$ had been in an abandoned house, on the street, or in similar settings. The number of times the adolescents had run away ranged from 1-51 times with a mean of eight runs $(\mathrm{SD}=11.2)$.

Adolescents ranged in age from 16 to 19 years with an average age of 17.4 years $(\mathrm{SD}=1.04)$. Fifty-nine percent were European American, 22\% were non-Hispanic African American, and 5\% were Hispanic. The remaining participants (14\%) self-identified as American Indian, Asian or Pacific Islander, or biracial. In regard to sexual orientation, 15\% were gay, lesbian, or bisexual. Sixty-two percent were born in a city with a population of 100,000 or more, $10 \%$ a suburb of a large city, $8 \%$ a medium sized city $50,000-100,000,8 \%$ a small city $10,000-50,000$, and $12 \%$ a small town or rural community of 10,000 or less. Adolescents were informed that this was a longitudinal study; informed consent was a two-stage process. First, the study was explained, and informed consent was obtained from the adolescent. They were assured that refusal to participate in the study, to answer specific questions, or to discontinue the interview process would have no effect on current or future services provided by the outreach agency in which the interviewer was placed. Second, all adolescents were asked if their parents could be contacted. If permission was granted, parents were contacted, informed consent was obtained, and they were asked to participate in a computer-assisted telephone in- 
terview. If the adolescent was sheltered, we followed shelter policies of parental permission for placement and the guidelines for granting permission. These policies were always based on state laws. In the few cases where the adolescents were under 18 years, not sheltered, and refused permission to contact parents, the adolescents were treated as emancipated minors in accord with National Institute of Health guidelines (Title 45, Part 46, Code of Federal Regulations, Department of Health and Human Services, 2001). A National Institute of Mental Health Certificate of Confidentiality was obtained to protect the respondent's statement regarding potentially illegal activities (e.g., drug use).

The first wave interview consisted of two parts. The first component was a social history and symptom scales. The respondent was then asked to meet for a second interview during which the diagnostic interview was conducted. Based on interviewer reports, approximately $90 \%$ of the adolescents who were approached for an initial interview and who met study criteria agreed to participate in the study. Of 455 respondents who completed the first interview, $94.3 \%(n=428)$ completed the second baseline interview. The respondents were paid $\$ 25$ for the first interview and $\$ 25$ for the second.

\section{Measures}

To measure whether adolescents were involved into the criminal justice system while on the street, we first asked homeless adolescents whether they had been arrested by the police and the date of the first arrest. Those who had their first arrest after their initial runaway were coded " 1 ," and those who had never been arrested were coded " 0. " Fiftyfive percent reported that they were arrested at least once after they ran away from home. In addition, to further understand the frequency and nature of their involvement with the criminal justice system, we asked how many times these adolescents were arrested, the reasons for arrest, and whether there were any charges after the arrests.

The UM-CIDI was used to assess lifetime major depressive episode, posttraumatic stress disorder, alcohol abuse, and drug abuse. The UM-CIDI is based on DSM-III-R criteria and represents the University of Michigan's revision to the CIDI (WHO, 1990) used in the National Comorbidity Study (NCS) (for information regarding the University of Michigan's revisions see Wittchen \& Kessler, 1994). The CIDI (WHO, 1990) from which the UMCIDI is derived is a well-established diagnostic instrument that has shown excellent interrater reliability, test-retest reliability, and validity for the five diagnoses that were used in this study. 
To assess behavioral problems, the conduct disorder module was used from the DISC-R. The DISC-R is a highly regarded, structured interview intended for use with trained interviewers who are not clinicians. It has been shown to have from good to excellent interrater and test-retest reliability (Jenson et al., 1995; Schaffer et al. 1993) and is considered a state-ofthe-science structured interview for use in assessing behavioral disorders of childhood and adolescence (Schaffer et al., 1993; Schwab-Stone et al., 1993; Weinstein, Noam, Grimes, Stone, \& Schwab-Stone, 1990).

The measurement of lifetime psychiatric comorbidity is based on the distribution of the three externalizing disorders (alcohol abuse, drug abuse, and conduct disorder) and the two internalizing disorders (major depression, and PTSD). A variable with nine exclusive categories was constructed: without any of the five disorders, only one externalizing disorder, only one internalizing disorder, only two externalizing disorders, only two internalizing disorders, one externalizing disorder and one internalizing disorder, two internalizing disorders and one externalizing disorder, two externalizing disorders and one internalizing disorder, and at least four disorders. Street adolescents with two or more internalizing or externalizing disorders were defined as having lifetime comorbid symptoms. About two-thirds (65.7\%) of these adolescents reported having at least two of the five mental disorders in their lifetime; one out of five $(21.37 \%)$ reported that they had at least four of the five lifetime mental disorders. In multivariate analysis, lifetime psychiatric comorbidity was then recoded into eight dummy variables with the first group (adolescents without any of the five mental disorders) as a reference group.

Age of adolescent at time of interview was calculated using the date of birth of the respondent and the date of the baseline interview. Age ranged from 16 to 19 with a mean age of 17.4 years $(\mathrm{SD}=1.04)$. Gender of adolescent was coded 0 for females and 1 for males (56\%, versus $44 \%$, respectively). Race was coded 1 for Non-Hispanic White and 0 for others; the majority (59\%) were Non-Hispanic White.

Adolescent sexual orientation was assessed by a question in which the adolescents identified themselves as straight, heterosexual, gay/lesbian, bisexual, never thought about it, something else, or confused or unsure. The variable was recoded so that any individual listing a nonheterosexual or unsure sexual identity was coded as nonheterosexual. Response categories were 1 for nonheterosexual and 0 for heterosexual.

Caretaker abuse/neglect was measured with a 13-item scale that asked adolescents how often a parent or adult caretaker who was supposed to be taking care of them ever punished them by making them go a full day without food or water, abandoned them for at least 24 hours, threw some- 
thing at them in anger, pushed them, slapped them, hit them with an object, beat them up with their fists, threatened or assaulted them with a weapon (Straus \& Gelles, 1990), and/or sexually abused them. Because an unequal number of neglect, physical abuse, and sexual abuse items were asked, items were weighted to give equal importance to the three indicators in the summed scale. Scale scores were coded such that the higher the score, the higher the rate of abuse. Cronbach's $\alpha$ for caretaker abuse/ neglect was .94 .

Adolescents were asked if they had ever spent one or more nights on the street in an abandoned building or another place out in the open. Those individuals who had not spent at least one night on the street were coded as 0 ; the rest were coded 1 . Approximately $49 \%$ of the sample had spent at least one night on the street.

Age on own was a single item that asked adolescents how old they were when they left home and were on their own for the first time. The mean age adolescents were first on their own was 13.4 years old $(\mathrm{SD}=2.97$ ).

Deviant subsistence strategies was measured by adolescents' self-report of the ways they obtained money and food (adapted from Whitbeck \& Simons, 1990). A list of ways people typically get money and food was presented to the youth, and they were asked if they had used any of these strategies. Some of these methods of obtaining money and food were defined as deviant subsistence strategies. Adolescents were asked to report if they had ever asked for spare-change for money or food, broken in and taken things away from a store or house, engaged in prostitution for money or for food, sold drugs for money, stole or shoplifted food, or engaged in dumpster diving for food. The summated scale has an a reliability of .63 and ranged from 0 to 6 with higher values suggesting greater involvement in deviant subsistence strategies.

\section{Analytic Strategy}

As our data could not differentiate if arrests occurred before running away with the exception of first arrest, youth who had been arrested before their first runaway were excluded. Although the truncation of explanatory variables may present some problems (Breen, 1996), the exclusion of these cases $(n=39)$ avoids a confounding association between prerunaway arrest and street risk factors. Ten more cases were deleted in the regression analysis owing to listwise deletion. Three hundred seventy-nine $(88.6 \%)$ cases were retained for the final analysis. Missing case analysis showed that youths excluded from final analysis left home earlier than those retained; however, no other differences were found in terms of demographic information (age, gender, race, or sexual orientation), fam- 
ily background (neglect and abuse at home), street exposure (ever on the street, use of deviant subsistence strategies), and frequency of arrests.

The distribution of offenses which resulted in homeless adolescents' postrunaway arrest is presented first. We then examined bivariate associations between individual mental disorders and various combinations of comorbidity and probability of arrest. Specifically, we compared the risk of arrest among adolescents with alcohol abuse, drug abuse, conduct disorder, major depression, or PTSD and those without any of the five mental disorders. The risk of arrest among those with various combinations of internalizing and externalizing disorders was also compared with nondisordered adolescents. Finally, we used multivariate logistic regression models to assess the unique associations by controlling for other risk factors such as street exposure.

\section{Results}

\section{Postrunaway Arrests and Distribution of Offense}

More than half $(57.3 \%, n=217)$ of homeless and runaway youth reported that they had been arrested at least once after the initial runaway, with the average of 4.4 . One-third (36.7\%) were arrested only one time, $21 \%$ two times, $11 \%$ three times, and $31 \%$ four or more times. As expected, males averaged more arrests than females (5.74, versus 3.02, respectively). The distribution of offenses for the first postrunaway arrest was examined (see Table 1). As expected, property crime was the most prevalent; about $20 \%$ were arrested for shoplifting or theft. Status offenses such as running away and drinking under age, simple assault, substance abuse, and public conduct disorder were also reported by some adolescents. After their initial arrest, about one-third (36\%) were sent to juvenile detention, less than one-third (29\%) were freed without any charge, $11 \%$ of them were sent to a group home, residential facility or shelter, and about one quarter (24\%) reported "other" outcomes (results not shown).

\section{Mental Disorders/Comorbidity and Postrunaway Arrest}

Table 2 presents the prevalence of the five mental disorders and various types of comorbidity among homeless adolescents. As expected, a large percentage of them had various externalizing and internalizing disorders, with about three quarters of them being conduct-disordered, onethird of them having major depression or PTSD, and about $40 \%$ being alcohol or drug abusers. Not surprisingly, the majority of them $(n=249$, $66 \%$ ) had comorbid disorders (see Table 2). 
Table 1. Distribution of Offenses of First Postrunaway Arrest Among Homeless and Runaway Youth $(N=217)$

\begin{tabular}{lrr}
\hline & $N$ & $\%$ \\
\hline Serious offenses & $\mathbf{6 7}$ & $\mathbf{3 0 . 9}$ \\
Violent crime & 5 & 2.3 \\
Rape/sexual offense & 2 & .9 \\
Aggravated assault & 3 & 1.4 \\
Property Crime & 62 & 28.6 \\
Shoplifting/theft & 44 & 20.3 \\
Burglary & 6 & 2.8 \\
Auto theft & 9 & 4.1 \\
Arson & 3 & 1.4 \\
Less serious offenses & $\mathbf{1 5 0}$ & $\mathbf{6 9 . 1}$ \\
Alcohol/drug offense & 20 & 9.2 \\
Simple assault & 31 & 14.3 \\
Status offense (runaway, under-age drinking) & 38 & 17.5 \\
Vandalism & 8 & 3.7 \\
Disorderly conduct & 5 & 2.3 \\
Family violence & 4 & 1.8 \\
Traffic violations & 5 & 2.3 \\
Others & 39 & 18.0 \\
\hline
\end{tabular}

Table 2 also compares the odds ratio of postrunaway arrest between adolescents diagnosed with mental disorders and comorbidity and nondisordered adolescents. Youth diagnosed with any of the five mental disorders had a significantly higher risk of arrest. However, significant associations between internalizing disorders such as major depression and PTSD and postrunaway arrest may be accounted for by comorbid antisocial behavior or substance abuse. Adolescents with mainly internalizing disorders (only two internalizing disorders, two internalizing disorders with one externalizing disorder, and one externalizing and one internalizing disorder) did not differ significantly from nondisordered youths. In contrast, those who had at least two externalizing disorders had much higher odds of being arrested, as did those who had at least four mental disorders reported the highest odds (odds ratio $=6.34$ ).

\section{Correlation Matrix}

Table 3 presents the bivariate correlations, means, and standard deviations for all study variables. Postrunaway arrest was significantly asso- 
Table 2. Prevalence of Mental Disorder and Comorbidity, and Comparison of Risk of Arrest between Homeless Adolescents Diagnosed with Mental Disorders and Nondisordered Youths

\begin{tabular}{|c|c|c|c|c|c|}
\hline Disorders & $n$ & $\%$ & $\begin{array}{l}\text { Odds Ratios } \\
\text { for Arrest }^{\mathrm{a}}\end{array}$ & $\begin{array}{r}95 \% \\
\text { Confid } \\
\text { s Bou } \\
\text { Lower }\end{array}$ & $\begin{array}{l}\text { Ince } \\
\text { lends } \\
\text { Upper }\end{array}$ \\
\hline \multicolumn{6}{|l|}{ Mental disorder ${ }^{\mathrm{b}}$} \\
\hline Alcohol abuse & 161 & 42.48 & 4.02 & 2.01 & 8.07 \\
\hline Drug abuse & 148 & 39.05 & 4.15 & 2.05 & 8.39 \\
\hline Conduct disorder & 282 & 74.41 & 3.15 & 1.63 & 6.07 \\
\hline Major depression & 118 & 31.13 & 2.55 & 1.25 & 5.20 \\
\hline PTSD & 137 & 36.15 & 2.40 & 1.19 & 4.81 \\
\hline \multicolumn{6}{|l|}{ Comorbidity $(n=249)^{\mathrm{c}}$} \\
\hline Only major depression+PTSD & 10 & 4.02 & .45 & .09 & 2.40 \\
\hline Only two externalizing disorders & 49 & 19.68 & 4.53 & 1.90 & 10.81 \\
\hline One externalzing+one internalizing disorder & 37 & 14.86 & 1.24 & .50 & 3.03 \\
\hline Two externalizing+one internalizing disorders & 58 & 23.29 & 2.97 & 1.32 & 6.67 \\
\hline Two internalizing+one externalizing disorders & 14 & 5.62 & 1.01 & .29 & 3.52 \\
\hline Four or more disorders & 81 & 32.53 & 6.34 & 2.84 & 14.18 \\
\hline
\end{tabular}

a The nondisordered group is used as reference group to calculate odds ratio for arrest.

$\mathrm{b}$ The diagnostic categories of individual mental disorders are not mutually exclusive. The prevalence is calculated based on the whole sample $(n=379)$.

c The categories of comorbidity are mutually exclusive. The percentage is calculated based on sample of adolescents with comorbid diagnoses $(n=249)$.

PTSD = posttraumatic stress disorder.

ciated with age, gender, race, exposure on the street and engagement in street subsistence strategies (see Table 3 ). In addition, mental health disorders, especially externalizing disorders such as substance abuse and conduct disorder, were significantly associated with postrunaway arrest; however, we did not find any significant association between internalizing disorders such as major depression and PTSD and involvement with the criminal justice system (see Table 3 ). The significant associations had small to moderate effect sizes (Cohen, 1988).

Logistic Regression Models: Mental Disorders/Comorbidity and Postrunaway Arrest

Situational risk factors and individual mental disorders affecting the probability of postrunaway arrest were investigated in a series of logistic 
Table 3. Mean, Standard Deviation, and Correlation for All Study Variables $(n=$ 379)

\begin{tabular}{|c|c|c|c|c|c|c|c|c|c|c|c|c|c|c|}
\hline & 1 & 2 & 3 & 4 & 5 & 6 & 7 & 8 & 9 & 10 & 11 & 12 & 13 & 14 \\
\hline 1 Arrest & - & & & & & & & & & & & & & \\
\hline 2 Age & $.15^{* *}$ & - & & & & & & & & & & & & \\
\hline 3 Male & $.19^{* *}$ & $.21^{* *}$ & - & & & & & & & & & & & \\
\hline 4 White & $-.11^{*}$ & .00 & .01 & - & & & & & & & & & & \\
\hline 5 Heterosexual & .07 & $-.12^{*}$ & $.11^{*}$ & -.05 & - & & & & & & & & & \\
\hline 6 Parental abuse & .06 & $.15^{* *}$ & -.08 & -.05 & $-.13^{*}$ & - & & & & & & & & \\
\hline 7 Age on own & $-.17^{* *}$ & .07 & -.05 & $.14^{* *}$ & -.08 & $-.23^{* *}$ & - & & & & & & & \\
\hline 8 On street & $.28^{* *}$ & $.31^{* *}$ & $.21^{* *}$ & $.13^{*}$ & -.07 & $.27^{* *}$ & -.03 & - & & & & & & \\
\hline 9 DSS & $.27^{* *}$ & $.23^{* *}$ & $.24^{* *}$ & .06 & $-.14^{* *}$ & $.20^{* *}$ & -.10 & $.41^{* *}$ & - & & & & & \\
\hline 10 Alcohol abuse & $.24^{* *}$ & $.13^{*}$ & .08 & .02 & $-.11^{*}$ & $.14^{* *}$ & -.09 & $.22^{* *}$ & $.34^{* *}$ & - & & & & \\
\hline 11 Drug abuse & $.24^{* *}$ & $.20^{* *}$ & $.11^{*}$ & .05 & -.08 & $.15^{* *}$ & -.07 & $.24^{* *}$ & $.38^{* *}$ & $.42^{* *}$ & - & & & \\
\hline 12 PTSD & .02 & .05 & $-.21^{* *}$ & .02 & $-.14^{* *}$ & $.34^{* *}$ & $-.12^{*}$ & .04 & $.13^{*}$ & $.11^{*}$ & $.13^{*}$ & - & & \\
\hline 13 Depression & .04 & $.14^{*}$ & -.07 & $.13^{*}$ & $-.12^{*}$ & $.24^{* *}$ & .01 & $.14^{* *}$ & .08 & $.10^{*}$ & .09 & $.30^{* *}$ & - & \\
\hline 14 Conduct disorder & $.28^{* *}$ & .03 & $.19^{* *}$ & -.07 & .05 & $.11^{*}$ & -.10 & $.11^{*}$ & $.32^{* *}$ & $.33^{* *}$ & $.31^{* *}$ & .06 & .06 & - \\
\hline M & .561 & 17.37 & .42 & .61 & .85 & 1.3913 & 3.23 & .48 & 1.32 & .43 & .39 & .37 & .32 & .76 \\
\hline SD & .50 & 1.04 & .49 & .49 & .36 & .79 & 3.04 & .50 & 1.62 & .50 & .49 & .48 & .47 & .43 \\
\hline
\end{tabular}

${ }^{*} p<.05 ;{ }^{* *} p<.01$.

DSS, deviant subsistence strategies; PTSD, posttraumatic stress disorder.

regression models (Table 4). The four control variables and family abuse and neglect were entered simultaneously in model 1 . Older youth $(b=$ $.23, \operatorname{Exp}(b)=1.26)$, male $(b=.71, \operatorname{Exp}(b)=2.03)$, and minorities $(b=-.46$, $\operatorname{Exp}(b)=.63$ ) were more likely to be arrested. No significant association was found between abuse and neglect and arrest.

In model 2, factors related to exposure on the street such as age at first runaway, time on the street, and use of deviant subsistence strategies were added. All of these variables were statistically significant. For each unit decrease of age at first run, the odds of being arrested increased by about $10 \%(b=-.10, \operatorname{Exp}(b)=.90)$. Youth who spent time on the street were over two times more likely to be arrested $(b=.92, \operatorname{Exp}(b)=2.52)$. For each unit increase in the measure of deviant subsistence strategies (e.g., selling or trading sex, panhandling, and stealing, etc.), the odds of being arrested increased more than $30 \%(b=.29, \operatorname{Exp}(b)=1.33)$.

After controlling for demographic variables and situational risk factors, each individual mental disorder was added in separate steps into the logistic regression model. Similar to the bivariate analysis, externalizing disorders such as alcohol abuse $(b=.72, \operatorname{Exp}(b)=2.06)$, drug abuse $(b=.66, \operatorname{Exp}(b)=1.94)$, and conduct disorder $(b=1.06, \operatorname{Exp}(b)=2.90)$ were significantly associated with being arrested after first runaway (model 3- 
Table 4. Logistic Regression Models Predicting First Postrunaway Arrest $(n=379)$

\begin{tabular}{|c|c|c|c|c|c|c|c|c|}
\hline \multirow[b]{2}{*}{ Independent Variable } & \multicolumn{2}{|c|}{ Model 1} & \multicolumn{2}{|c|}{ Model 2} & \multicolumn{2}{|c|}{ Model 3} & \multicolumn{2}{|c|}{ Model 4} \\
\hline & $b$ & $\operatorname{Exp}(b)$ & $b$ & $\operatorname{Exp}(b)$ & $b$ & $\operatorname{Exp}(b)$ & $b$ & $\operatorname{Exp}(b)$ \\
\hline Age & .23 & $1.26^{*}$ & .12 & 1.13 & .11 & 1.12 & .10 & 1.10 \\
\hline Male & .71 & $2.03^{* *}$ & .35 & 1.42 & .38 & 1.46 & .36 & 1.44 \\
\hline White & -.46 & $.63^{*}$ & -.61 & $.54^{*}$ & -.62 & $.54^{*}$ & -.64 & $.53^{*}$ \\
\hline Heterosexual & .42 & 1.53 & .59 & $1.81+$ & .68 & $1.97+$ & .62 & $1.86+$ \\
\hline Parental abuse/neglect & .18 & 1.20 & -.16 & .85 & -.19 & .83 & -.18 & .83 \\
\hline Age on own & & & -.10 & $.90^{* *}$ & -.10 & $.90^{*}$ & -.10 & $.90^{*}$ \\
\hline Ever on street & & & .92 & $2.52^{* *}$ & .90 & $2.47^{* *}$ & .90 & $2.47^{* *}$ \\
\hline DSS & & & & & .22 & $1.25^{*}$ & .23 & $1.26^{*}$ \\
\hline Alcohol abuse & & & & & & & .72 & $2.06^{* *}$ \\
\hline Drug abuse & & & & & & & .66 & $1.94^{*}$ \\
\hline Conduct disorder & & & & & & & & \\
\hline Major depression & & & & & & & & \\
\hline PTSD & & & & & & & & \\
\hline One externalizing ${ }^{\mathrm{b}}$ & & & & & & & & \\
\hline One internalizing & & & & & & & & \\
\hline Two externalizing & & & & & & & & \\
\hline Two internalizing & & & & & & & & \\
\hline $\begin{array}{l}\text { One externalizing + } \\
\text { one internalizing }\end{array}$ & & & & & & & & \\
\hline $\begin{array}{c}\text { Two externalizing + } \\
\text { one internalizing }\end{array}$ & & & & & & & & \\
\hline $\begin{array}{l}\text { Two internalizing + } \\
\text { one externalizing }\end{array}$ & & & & & & & & \\
\hline Four or more disorders & & & & & & & & \\
\hline Constant & -4.36 & .01 & -1.34 & .26 & -1.46 & .23 & -1.07 & .34 \\
\hline Model $\chi^{2}$ & $25.76^{* *}$ & & $67.00^{* *}$ & & $75.47^{* *}$ & & $73.73^{* *}$ & \\
\hline$\chi^{2}$ change & 1.62 & & $10.84^{* *}$ & & $8.47^{* *}$ & & $6.73^{* *}$ & \\
\hline
\end{tabular}

\begin{tabular}{lrrrrrrrrr}
\hline & \multicolumn{2}{c}{ Model 5 } & \multicolumn{2}{c}{ Model 6 } & \multicolumn{2}{c}{ Model 7 } & \multicolumn{2}{c}{ Model 8 } \\
Independent Variable & $b$ & $\operatorname{Exp}(b)$ & $b$ & $\operatorname{Exp}(b)$ & $b$ & $\operatorname{Exp}(b)$ & $b$ & $\operatorname{Exp}(b)$ \\
\hline Age & .15 & 1.16 & .12 & 1.13 & .11 & 1.12 & -.04 & .97 \\
Male & .25 & 1.28 & .37 & 1.45 & .36 & 1.44 & .38 & 1.46 \\
White & -.56 & $.57^{*}$ & -.62 & $.54^{*}$ & -.63 & $.53^{*}$ & -.02 & .99 \\
Heterosexual & .53 & 1.70 & .60 & $1.83+$ & .61 & $1.85+$ & .63 & 1.88 \\
Parental abuse/neglect & -.21 & .81 & -.18 & .84 & -.19 & .83 & -.18 & .83 \\
Continued & & & & & & & &
\end{tabular}


Table 4, Continued.

\begin{tabular}{|c|c|c|c|c|c|c|c|c|}
\hline \multirow[b]{2}{*}{ Independent Variable } & \multicolumn{2}{|c|}{ Model 5} & \multicolumn{2}{|c|}{ Model 6} & \multicolumn{2}{|c|}{ Model 7} & \multicolumn{2}{|c|}{ Model 8} \\
\hline & $b$ & $\operatorname{Exp}(b)$ & $b$ & $\operatorname{Exp}(b)$ & $b$ & $\operatorname{Exp}(b)$ & $b$ & $\operatorname{Exp}(b)$ \\
\hline Age on own & -.10 & $.90^{*}$ & -.10 & $.90^{*}$ & -.10 & $.90^{*}$ & -.12 & $.89^{* *}$ \\
\hline Ever on street & 1.02 & $2.77^{* *}$ & .93 & $2.54^{* *}$ & .92 & $2.51^{* *}$ & .92 & $2.50^{* *}$ \\
\hline DSS & .19 & $1.21^{*}$ & .28 & $1.33^{* *}$ & .29 & $1.33^{* *}$ & .15 & 1.16 \\
\hline \multicolumn{9}{|l|}{ Alcohol abuse } \\
\hline \multicolumn{9}{|l|}{ Drug abuse } \\
\hline Conduct disorder & 1.06 & $2.90^{* *}$ & & & & & & \\
\hline Major depression & & & .09 & 1.10 & & & & \\
\hline \multicolumn{9}{|l|}{ PTSD .19 1.21} \\
\hline One externalizing ${ }^{\mathrm{a}}$ & & & & & & & .11 & 1.12 \\
\hline One internalizing & & & & & & & -.59 & .55 \\
\hline Two externalizing & & & & & & & .94 & $2.55^{*}$ \\
\hline Two internalizing & & & & & & & -.97 & .38 \\
\hline $\begin{array}{l}\text { One externalizing + } \\
\text { one internalizing }\end{array}$ & & & & & & & -.07 & .93 \\
\hline $\begin{array}{l}\text { Two externalizing + } \\
\text { one internalizing }\end{array}$ & & & & & & & .53 & 1.70 \\
\hline $\begin{array}{l}\text { Two internalizing + } \\
\text { one externalizing }\end{array}$ & & & & & & & -.14 & .87 \\
\hline Four or more disorders & & & & & & & 1.36 & $3.91^{* *}$ \\
\hline Constant & -2.43 & .09 & -1.35 & .26 & -1.23 & .29 & .98 & 2.67 \\
\hline Model $\chi^{2}$ & $80.68^{* *}$ & & $67.12^{* *}$ & & $67.52^{* *}$ & & $90.28^{* *}$ & \\
\hline$\chi^{2}$ change & $13.67^{* *}$ & & .12 & & .52 & & $25.12^{* *}$ & \\
\hline
\end{tabular}

$+p<.10 ;^{*} p<.05 ;{ }^{* *} p<.01$.

a Comorbidity was coded into eight dummy variables. The reference category was nondisordered youth.

DSS = deviant subsistence strategies; PTSD = posttraumatic stress disorder.

model 5). In contrast, major depression (model 6) and PTSD diagnoses (model 7) were not significantly associated with postrunaway arrest.

Model 8 compared the risk of arrest between adolescents with different combinations of comobidity and nondisordered youths. As expected, those with four or more diagnoses had the highest probability of being arrested $(b=1.36, \operatorname{Exp}(b)=3.91)$. In addition, adolescents with two externalizing disorders were 2.6 times more likely to be arrested than nondisordered youths. Consistent with bivariate analysis, there were no significant differences between adolescents with mainly internalizing disorders (two internalizing disorders, one internalizing disorder and one externalizing disorder, or two internalizing disorders and one externalizing dis- 
orders) and nondisordered youth. Surprisingly, we also found that adolescents with two externalizing disorders and one internalizing disorder did not differ significantly from nondisordered youth.

Interactions between each mental disorders and comorbidity, familial abuse and neglect, and street situational variables were examined (results not shown). There were two significant interactions between substance abuse and caretaker abuse and neglect. Specifically, adolescents who were abused/neglected at home and diagnosed as alcohol abusers were more likely to be arrested than those without a family abuse/neglect history but with alcohol abuse diagnosis. Similarly, those with a family abuse/neglect history and diagnosed as drug abusers were more likely to be arrested, while adolescents without dysfunctional family lives had similar odds of arrest in spite of drug abuse status.

\section{Discussion and Conclusion}

Many youth in the current study experienced high rates of mental disorders and involvement with the criminal justice system. Consistent with previous literature (Kaufman \& Widom, 1999; Hagan \& McCarthy, 1997; Whitbeck \& Hoyt, 1999), homeless adolescents reported a high rate of postrunaway arrest. More than half of adolescents reported at least an arrest after their first runaway, with an average of 4.4 times. Similar to previous research (Snow et al., 1989), most offenses were nonviolent and not particularly dangerous, with the majority of them related to use of street subsistence strategies such as stealing food or money, status offenses, substance abuse, or public disorderly conduct.

Our hypotheses about the probability of arrest and mental disorders are supported. Consistent with Hodgins's suggestion (1988), the current study found that involvement with the criminal justice system was associated with only certain mental disorders. Postrunaway arrest was associated with externalizing disorders such as alcohol abuse, drug abuse, and conduct disorder. Although alcohol/drug use is illegal for homeless and runaway adolescents, the practice of substance use is highly prevalent in this population, with most street youth reporting use of alcohol or drugs as coping strategies while on the street (Hagan \& McCarthy, 1997; Whitbeck \& Hoyt, 1999). However, only a small percentage of these adolescents were arrested because of drug use and underage drinking in this sample $(n=24)$. Thus, we argue that the significant associations between alcohol abuse/drug abuse and arrest is not because of alcohol/drug use per se; instead, it indicates that adolescents who have reached the clinical threshold of substance abuse are significantly different from those who 
have not met criteria. Abuse of alcohol/drugs may negatively affect adolescents' cognitive ability and behavioral patterns, thus increasing their visibility and detection by the police (Belcher, 1988; Hodgins \& Janson, 2002; Robertson, 1988; Snow et al., 1989). In addition, homeless adolescents who abuse alcohol or drugs are more likely to engage in violent and property crime, such as stealing or robbery to obtain money (Fergusson \& Horwood, 2000; Friedman, 1998; Snow et al., 1989).

In contrast, although bivariate analysis showed a significant association between internalizing disorders such as major depression and PTSD and postrunaway arrest, the relationship was nonsignificant when externalizing mental disorders were taken into account. We found no significant differences between those with only internalizing disorders and nondisordered youths. Multivariate analyses provided similar results; after antisocial behavior such as use of street survival strategies was controlled, there was no statistically significant association between internalizing disorders and postrunaway arrest. As suggested by Coster and Heimer (2001), the significant bivariate associations may be because of common antecedents, such as abuse and neglect at home and use of street survival strategies.

Our research also supports the differential associations between comorbidity and involvement with the criminal justice system (Hodgins, 1993; Hodgins \& Janson, 2002; Kessler, 1994, 1995; Kessler et al., 1995; Kessler et al., 1998). First, homeless and runaway adolescents with multiple externalizing disorders were at a much higher risk of arrest. Consistent with previous studies, comorbid diagnoses of alcohol and drug use disorders, or comorbid diagnoses of substance abuse and antisocial behavior on the street dramatically increased youths' risk of arrest (Hodgins, 1993; Hodgins \& Janson, 2002; Snow et al., 1989). Second, compared with nondisordered youths, those with only internalizing disorders or those with mainly internalizing disorders (for instance, multiple internalizing disorders but only one externalizing disorders) had similar arrest rates. Interestingly, adolescents with two externalizing disorders and one internalizing disorder were not significantly different from nondisordered adolescents. This may be because of the fact that adolescents with depression/PTSD are more likely to withdraw from the society, thus decreasing the strength between externalizing disorders and arrest. Moreover, adolescents with multiple internalizing and externalizing disorders had the highest probability of arrest. We suspect, while some adolescents with internalizing disorders are likely to withdraw, inadequate and/or inappropriate treatment may increase others' reliance on substance abuse as a coping strategy while on the street, which leads to an elevated level of involvement with the criminal justice system (Friedman, 1998; Hodgins \& Janson, 2002). 
The current study makes an important contribution to our understanding of mental disorders and arrest among runaway and homeless youth. However, some limitations need to be addressed. First, it is difficult at best to randomly sample the runaway and homeless adolescent population; therefore, these data are not based on a probability sample. The fact that the data are collected from multiple sites in the Midwest, however, increases the reliability and generalizability of the findings. Second, although we examine the associations between the five diagnostics and postrunaway arrests, some severe mental disorders, such as schizophrenia and schizophreniform, are not considered. These severe mental disorders may affect homeless and runaway youth in ways that may influence antisocial tendencies (Bloom, Williams, \& Bigelow, 1992; Hiller, Knight, Broome, \& Simpson, 1996; Wessley, 1997). In addition, it is likely that a proportion of adolescents with lifetime comorbidity did not have these disorders concurrently, potentially obscuring processes leading to increases in probability of arrest. Third, cross-sectional data are used in this study, which may raise questions about the causal relationship among certain variables. For example, we used lifetime mental disorders to predict criminal justice contact; it is possible that arrest could result in the development of specific mental disorder such as PTSD or comorbid symptoms. Further analysis of onset of mental disorders, however, suggested that the majority of these adolescents had onset before they were on the street; nonetheless, future longitudinal studies are needed to examine the direction of this causal relationship.

Adolescents with externalizing disorders create unique challenges for agency staff because they may not seek help or utilize the services that are provided but rather continue on a destructive trajectory. Federal funding to support mental health services are sorely needed. Outreach activities should be directed at the most troubled youth, and counseling services and programmatic decisions should deal with these disorders before they devolve into official police contact. On the other hand, youth with internalizing disorders do not appear to be at-risk for arrest, but their coping strategies could be impaired sufficiently to increase their vulnerability to street victimization, and without appropriate treatment their symptoms could persist over the life course. While comorbid youth need a multi-pronged approach, mental health services could be better allocated if we systematically examined the trajectories of street youth with mental illness.

Clearly, a more detailed study of the nature of the relationship between mental disorder, comorbidity, and arrest among homeless and runaway adolescents should be pursued. Toward this end, the importance of the current study lies in two areas. First, this study examined the associa- 
tion between individual mental disorder and involvement with the criminal justice system. The differential effects of externalizing disorders (e.g., substance abuse and conduct disorder) and internalizing disorders (e.g., posttraumatic stress disorder and major depression) suggest that a broad definition of mental disorder used by previous studies is not appropriate. Mentally disordered homeless youth are more likely to be arrested, primarily because of externalizing disorders such as conduct disorder and substance abuse. Future studies should examine other externalizing disorders, as well as more severe mental disorders such as schizophrenia and schizophreniform. Second, as Kessler et al. $(1995,1998)$ suggest, we examined the associations between specific types of comorbidity and involvement with the criminal justice system. Our results suggest that comorbidity, such as comorbid substance abuse and conduct disorders, and especially comorbid internalizing disorder and multiple externalizing disorders increase the odds of arrest. More research is needed to disentangle the association between specific types of comorbidity, such as major mental disorders and substance abuse, and violence and crime among homeless adolescents. In addition, longitudinal studies exploring the causal association between comorbidity and arrest, as well as the mechanism, which leads to arrest are needed. Future studies should collect more detailed information on early mental disorder, street deviant activities, and involvement with the criminal justice system, as well as the situational and interpersonal dynamics that lead to the onset of mental disorder and law violations.

\section{Acknowledgment}

This research was funded by the National Institute of Mental Health (MH 57110).

\section{References}

Agnew, R. (1992). Foundation for a general strain theory of crime and delinquency. Criminology, 30, 47-87.

Baron, S. W., \& Hartnagel, T. F. (1997a). Attributions affect and crime: Street youths' reactions to unemployment. Criminology, 35(3), 409-432.

Baron, S. W., \& Hartnagel, T. F. (1997b). Street youth and criminal violence. Journal of Research in Crime and Delinquency, 35(2), 166-192.

Belcher, J. R. (1988). Are jails replacing the mental health system for the homeless mentally ill? Community Mental Health Journal, 24, 185-94.

Bloom, J. D., Williams, M. H., \& Bigelow, D. A. (1992). The involvement of schizophrenic insanity acquittees in the mental health and criminal justice systems. Clinical Forensic Psy- 
chiatry, 15, 591-604.

Booth, R. E., \& Zhang, Y. (1996). Severe aggression and related conduct problems among runaway and homeless adolescents. Psychiatric Services, 471, 75-80.

Breen, R. (1996). Regression models: Censored, sample-selected or truncated data. Thousand Oaks, CA.: Sage Publications.

Brenda, B. (2003). Discriminators of suicide thoughts and attempts among homeless veterans who abuse substance. Suicide and Life-Threatening Behavior, 33(4), 430-443.

Brezina, T. (1996). Adapting to strain: An examination of delinquent coping responses. Journal of Research in Crime and Delinquency, 34, 39-60.

Brezina, T. (2000). Delinquent problem-solving: An interpretative framework for criminological theory and research. Journal of Research in Crime and Delinquency, 37, 3-30.

Burt, M. R. (1996). Practical methods for counting homeless people: A manual for state and local jurisdictions (2nd ed.). Washington, DC: Urban Institute.

Cauce, A. M., Paradise, M., Ginzler, J., Embry, L., Morgan, C., \& Lohr, Y., et al. (2000). The characteristics and mental health of homeless adolescents: Age and gender differences. Journal of Emotional and Behavioral Disorders, 8, 220-239.

Chen, X., Tyler, K. A., Whitbeck, L. B., \& Hoyt, D. R. (2004). Early sexual abuse, street adversity, and drug use among female homeless and runaway adolescents in the Midwest. Journal of Drug Issues, 1, 1-22.

Cohen, J. (1988). Statistical power analysis for the behavioral sciences. Hillsdale, NJ: Erlbaum.

Coster, S., \& Heimer, K. (2001). The relationship between law violation and depression: An interactionist analysis. Criminology, 39(4), 799-836.

Crichton, J. (1999). Mental disorders and crime. Journal of Forensic Psychiatry, 10(3), 659-678.

Department of Health and Human Services. (2001). Protection of Human Subjects Code of Federal Regulations Title 45 Public Welfare. Department of Health and Human Services National Institutes of Health Office of Protection from Research Risks Part 46. Revised November 132001.

Desai, R., Lam, J., \& Rosenheck, R. (2000). Childhood risk factors for criminal justice involvement in a sample of homeless people with serious mental illness. The Journal of Nervous and Mental Disease, 188(6), 324-332.

Feitel, B., Margetson, N., Chamas, J., \& Lipman, C. (1992). Psychosocial background and behavioral and emotional disorders of homeless and runaway youths. Hospital and Community Psychiatry, 43, 115-159.

Fergusson, D. M., \& Horwood, L. J. (2000). Alcohol abuse and crime: A fixed-effects regression analysis. Addiction, 95(10), 1525-1536.

Fischer, P. J. (1988). Criminal activity among the homeless: A study of arrests in Baltimore. Hospital and Community Psychiatry, 39, 46-51.

Forthofer, M. S., Kessler, R. C., Story, A. L., \& Gotlib, I. H. (1996). The effects of psychiatric disorders on the probability and timing of first marriage. Journal of Health and Social Behavior, 37, 121-132.

Friedman, A. S. (1998). Substance use/abuse as a predictor to illegal and violent behavior: A review of the relevant literature. Aggression and Violent Behavior, 3(4), 339-355.

Hagan, J., \& McCarthy, B. (1997). Mean streets: Youth crime and homelessness. New York: Cambridge University Press.

Hiday, V. A. (1999). Mental illness and the criminal justice system. In A. V. Horwitz, \& T. L. Scheid (Eds.), A handbook for the study of mental health: Social contexts, theories, and systems (pp. 508-525). New York: Cambridge University Press. 
Hiller, M. L., Knight, K., Broome, K. M., \& Simpson, D. (1996). Compulsory communitybased substance abuse treatment and the mentally ill criminal offender. The Prison Journal, 76(2), 180-191.

Hodgins, S. (1988). Antisocial behavior of persons suffering from mental disorders. In W. Buikhuisen, \& S. A. Medick (Eds.), Explaining criminal behavior: Interdisciplinary approaches. New York: E. J. Brill.

Hodgins, S. (1993). Mental disorder and crime. Newbury Park, CA: Sage Publications.

Hodgins, S., \& Janson, C. (2002). Criminality and violence among the mentally disordered: The Stockholm Metropolitan Project. New York: Cambridge University Press.

Hodgins, S., Mullersberner, R., \& Maden, A. (2001). Violence, crime and mentally disordered offenders: Concepts and methods for effective treatment and prevention. Criminal Justice, 1(2), 235-236.

Jenson, P., Roper, M., Fisher, P., Piacenti, J., Camino, G., \& Richters, J., et al. (1995). Testretest reliability of the diagnostic interview schedule for children DISC.2.1. Archives of General Psychiatry, 52, 67-71.

Kaufman, J., \& Widom, C. (1999). Childhood victimization, running away, and delinquency. Journal of Research in Crime and Delinquency, 36(4), 347-370.

Kessler, R. C. (1994). The National Comorbidity Survey of the United States. International Review of Psychiatry, 6, 365-376.

Kessler, R. C. (1995). Epidemiology of psychiatric comorbidity. In M. T. Tsuang, M. Tohen, \& G. E. Zahner (Eds.), Textbook in psychiatric epidemiology (pp. 179-198). New York: Wiley-Liss.

Kessler, R. C., Foster, C. L., Saunders, W. B., \& Stang, P. E. (1995). Social consequences of psychiatric disorders, I: Educational attainment. American Journal of Psychiatry, 152, 1026- 1032.

Kessler, R. C., Walters, E. E., \& Forthofer, M. S. (1998). The social consequences of psychiatric disorders, III: Probability of marital stability. American Journal of Psychiatry, 155, 1092-1096.

Kipke, M. D., Montgomery, S. B., Simon, T. R., \& Iverson, E. F. (1997). “Substance abuse” disorders among runaway and homeless youth. Substance Use E Misuse, 32(7-8), 969-986.

Koegel, P., Burnam, M., \& Morton, J. (1996). Enumerating homeless people: Alternative strategies and their consequences. Evaluation Review, 20, 378-403.

Loeber, R., \& LeBlanc, M. (1990). Toward a developmental criminology. In M. Tonry, \& N. Morris (Eds.), Crime and justice: An annual review of research (pp. 375-473). Chicago: University of Chicago Press.

Martell, D. A., Rosner, R., \& Harmon, R. B. (1995). Base-rate estimates of criminal behavior by homeless mentally ill persons in New York City. Psychiatric Services, 46(6), 596-601.

McCarthy, B., \& Hagan, J. (1992). Surviving on the street: The experiences of homeless youth. Journal of Adolescent Research, 74, 412-430.

McCaskill, P., Toro, P., \& Wolfe, S. (1998). Homeless and matched housed adolescents: A comparative study of psychopathology. Journal of Clinical Child Psychology, 27, 306-319.

Mulvey, E. P. (1994). Assessing the evidence of a link between mental illness and violence. Hospital and Community Psychiatry, 45, 663-8.

Robertson, G. (1988). Arrest patterns among mentally disordered offenders. British Journal of Psychiatry, 153, 313-16.

Robins, L. N. (1993). Childhood conduct problems adult psychopathology and crime. In Hodgins (Eds.), Mental disorder and crime. London: Sage.

Schaffer, D., Schwab-Stone, M., Fisher, P., Cohen, P., Piacentini, J., \& Davies, M., et al. (1993). 
The Diagnostic Interview Schedule for Children-revised version DISC-R: I. Preparation field testing inter-rater reliability and acceptability. Journal of the American Academy of Child and Adolescent Psychiatry, 32, 643-650.

Schwab-Stone, M., Fisher, P., Piacentini, J., Schaffer, D., Davies, M., \& Briggs-Gowan, M. (1993). The diagnostic interview schedule for children-revised version DISC-R: II. Testretest reliability. Journal of the American Academy of Child and Adolescent Psychiatry, 32, 651-657.

Silver, E. (2002). Mental disorder and violent victimization: The mediating role of involvement in conflicted social relationships. Criminology, 4(1), 191-212.

Simpson, C., \& Simpson, D. (1997). Coping with post-traumatic stress disorder. New York: New York Rosen Public Group.

Snow, D., Baker, S., \& Anderson, L. (1989). Criminality and homeless men: An empirical assessment. Social Problems, 36(5), 532-549.

Steadman, H. J., Mulvey, E. P., Monahan, J., Robbins, P. C., Appelaum, P. S., \& Grisso, T., et al. (1998). Violence by people discharged from acute psychiatric inpatient facilities and by others in the same neighborhoods. Archives of General Psychiatry, 55, 393-401.

Straus, M., \& Gelles, R. (1990). Physical violence in American families. New Brunswick, NJ: Transaction Publishers.

Stueve, A., \& Link, B. G. (1997). Violence and psychiatric disorders: Results from an epidemiological study of young adults in Israel. Psychiatric Quarterly, 68, 327-42.

Tomasson, K., \& Vaglum, P. (1998). Social consequences of substance abuse: The impact of comorbid psychiatric disorder: A prospective study of a nation-wide sample of treatment-seeking patients. Scandinavian Journal of Social Medicine, 26(1), 63-70.

Tyler, K. A., Hoyt, D. R., Whitbeck, L. B., \& Cauce, A. M. (2001). The impact of childhood sexual abuse on later sexual victimization among runaway youth. The Journal of Research on Adolescence, 11(2), 151-176.

Weinstein, S., Noam, G., Grimes, K., Stone, K., \& Schwab-Stone, M. (1990). Convergence of DSM-III diagnoses and self-reported symptoms in child and adolescent inpatients. Journal of the American Academy of Child and Adolescent Psychiatry, 19, 627-634.

Wessley, S. (1997). The epidemiology of crime violence and schizophrenia. The British Journal of Psychiatry, 170(32), 8-11.

Whitbeck, L. B., Chen, X., Hoyt, D. R., Tyler, K., \& Johnson, K. (2004). Mental disorders, subsistence strategies, and victimization among gay, lesbian, and bisexual homeless and runaway adolescents. The Journal of Sex Research, 41(4), 329-342.

Whitbeck, L. B., \& Hoyt, D. R. (1999). Nowhere to grow. Hawthorne, NY: Aldine De Gruyter.

Whitbeck, L. B., Johnson, K., Hoyt, D. R., \& Cauce, A. M. (2004). Mental disorder and comorbidity among runaway and homeless adolescents. Journal of Adolescent Health, 35(2), 132-140.

Whitbeck, L. B., \& Simons, R. L. (1990). Life on the streets: The victimization of runaway and homeless adolescents. Youth and Society, 22, 108-125.

Wittchen, H., \& Kessler, R. C. (1994). Modifications of the CIDI in the National Comorbidity Study: The development of the UM-CIDI. Ann Arbor, MI: NCS Working Paper \#2.

World Health Organization. (1990). Composite International Diagnostic Interview (CIDI). Version 1.0. Geneva, Switzerland: WHO. 